University of Wollongong

Research Online

Faculty of Engineering and Information

Faculty of Engineering and Information

Sciences - Papers: Part A

Sciences

$1-1-2012$

\title{
SAX-based decomposition of non-stationary power quality waveforms
}

\author{
M J. Afroni \\ University of Wollongong,mja763@uowmail.edu.au \\ Darmawan Sutanto \\ University of Wollongong, soetanto@uow.edu.au \\ D Stirling \\ University of Wollongong, stirling@uow.edu.au
}

Follow this and additional works at: https://ro.uow.edu.au/eispapers

Part of the Engineering Commons, and the Science and Technology Studies Commons

Research Online is the open access institutional repository for the University of Wollongong. For further information contact the UOW Library: research-pubs@uow.edu.au 


\title{
SAX-based decomposition of non-stationary power quality waveforms
}

\author{
Abstract \\ The Hilbert Huang Transform (HHT) is a powerful tool for Power Quality (PQ) classifications. One of the \\ main advantages of the HHT is its ability to analyze non-stationary complex waveforms with very good \\ time resolution. However, like other waveform classification techniques, it has difficulty in resolving the \\ instant of sudden changes in the waveform. To overcome the above problems, SAX (Symbolic Aggregate \\ ApproXimation) method is proposed to convert the signal into symbols which facilitates a pattern \\ detector algorithm to identify the border of the stationary signals within a non-stationary signal. Results \\ from simulations will be provided and discussed. (C) 2012 IEEE. \\ Keywords \\ stationary, quality, non, power, decomposition, sax, waveforms \\ Disciplines \\ Engineering | Science and Technology Studies \\ Publication Details \\ M. J. Afroni, D. Sutanto \& D. Stirling, "SAX-based decomposition of non-stationary power quality \\ waveforms," in Proceedings of International Conference on Harmonics and Quality of Power, ICHQP, 2012, \\ pp. 829-834.
}




\title{
SAX-based Decomposition of Non-Stationary Power Quality Waveforms
}

\author{
M. J. Afroni, D. Sutanto, Senior Member, IEEE, and D. Stirling, Member, IEEE
}

\begin{abstract}
The Hilbert Huang Transform (HHT) is a powerful tool for Power Quality (PQ) classifications. One of the main advantages of the HHT is its ability to analyze non-stationary complex waveforms with very good time resolution. However, like other waveform classification techniques, it has difficulty in resolving the instant of sudden changes in the waveform. To overcome the above problems, SAX (Symbolic Aggregate ApproXimation) method is proposed to convert the signal into symbols which facilitates a pattern detector algorithm to identify the border of the stationary signals within a non-stationary signal. Results from simulations will be provided and discussed.
\end{abstract}

Index Terms-- Hilbert Huang Transform, Power Quality, Harmonics, SAX.

\section{INTRODUCTION}

$\mathrm{H}$ ARMONICS and other typical power quality events such as voltage sags and swells, transients and flickers have the potential to cause malfunctions and inefficiencies [1]. The operational and financial cost caused by disturbances in power supply quality can be very significant for many industries. Therefore, there is an increasing need for power quality monitoring and methods to decompose the signals to their components. [2, 3].

Some common methods have been used to decompose PQ events such as Fourier transforms, Fast Fourier Transform (FFT) [4], wavelets [5], and recently Hilbert Huang Transform (HHT) [6]. Each of these techniques has its strengths and weaknesses. While FFT performs very well when dealing with stationary periodic signals, it cannot work with non-stationary signals whose frequency, amplitude and phase vary over time. However, most of the issues in power quality are usually nonstationary and noisy in nature, such as swell and sag and harmonics which are usually varying in time, Some techniques have been developed to make FFT works for such nonstationary signals including the short-time Fourier transform (STFT) which use windowing technique to concentrate the FFT [7] on a smaller area of the whole signal. However, there is always a compromise between frequency and time resolution which is referred to as the Heisenberg inequality where $\Delta t \Delta f \geq 1 / 4 \pi[8]$.

This work was supported by the Indonesian Higher Degree Education Scholarship (DIKTI) and the Endeavour Energy Power Quality and Reliability Centre (EEPQRB) at the University of Wollongong.

M.J. Afroni, D. Sutanto and D. Stirling are with the Department of Electrical, Computer and Telecommunication Engineering, University of Wollongong, NSW-2500, Australia (e-mail: mja763@uowmail.edu.au, soetanto@elec.uow.edu.au, strirling@elec.uow.edu.au ).
Wavelet uses techniques similar to STFT concentrating on some sections or windows of the signal but using window functions or wavelets such as Daubechies, Morlet wavelets [5], etc. The correct choice of wavelets can help in the detection and localization of the disturbances [9], [10]. However, the success of identifying PQ events relies to some degree on the choice of the wavelet [4] and once a wavelet function is chosen, it will have to be used to analyze all the data, and hence the wavelet analysis is not adaptive to varying disturbances.

HHT is a relatively new method to decompose signals into their components and are well suited for analyzing stationary and non-stationary signals. However, our preliminary results show that HHT has difficulties in identifying transition periods.

To overcome the above difficulties, this paper will propose a novel SAX algorithm which will be used to identify the transition times of the non-stationary signals. Once identified, each segment can be decomposed using HHT.

\section{THE HILBERT HUANG TRANSFORM}

\section{A. Introduction to the Hilbert Huang Transform}

The Hilbert Huang transform consists of two distinct processes. First the signal to be analyzed is decomposed using the Empirical Mode Decomposition (EMD) process into Intrinsic Mode Functions (IMFs) that have meaningful instantaneous frequency, amplitude and phase [11]. The EMD decomposes the signals into IMFs in such a way that the IMFs are sorted from the highest frequency to the lowest frequency, i.e., the first IMF contains the highest frequency of each event in the signal. Once the signal is decomposed into IMFs, the Hilbert Transform can then be applied to each IMF giving the instantaneous magnitude and instantaneous frequency vs. time. This combination of the EMD process and the Hilbert transform is known as the HHT. The HHT is well suited to non-linear and non-stationary time series data and thus is the perfect candidate for PQ event classifications. Further, the HHT method provides intuitive visual information of the frequency and magnitudes contained in the signal, unlike the Wavelet Transform.

\section{B. Empirical Mode Decomposition(EMD) [12]}

The first step in applying HHT is to decompose the signal $\mathrm{S}(\mathrm{t})$ into $\operatorname{IMF}(\mathrm{s})$ by using the EMD process. As the signal is being decomposed, each IMF has to satisfy the following conditions [7]. 
(a) There is exactly one zero between any two consecutive local extrema.

(b) The "local mean" have to be zero

The steps to carry out the EMD process are as follows[6]:

1. Find out local maxima and minima of the signal $\mathrm{S}(\mathrm{t})$

2. By using cubic spline interpolation, connect all of the maxima to get maxima envelope $\mathrm{C}_{\max }(\mathrm{t})$ and connect all of the minima to get minimum envelope $\mathrm{C}_{\min }(\mathrm{t})$.

3. Calculate the mean of the two envelopes

$$
\mathrm{C}_{\text {mean }}(\mathrm{t})=\left(\mathrm{C}_{\max }(\mathrm{t})+\mathrm{C}_{\text {min }}(\mathrm{t})\right) / 2
$$

4. Calculate the first potential IMF known as a proto-mode function $\mathrm{P}_{\mathrm{mfl}}(\mathrm{t})$, $\mathrm{P}_{\mathrm{mfl}}(\mathrm{t})=\mathrm{S}(\mathrm{t})-\mathrm{C}_{\text {mean }}(\mathrm{t})$.

5. Test whether $\mathrm{P}_{\mathrm{mfl}}(\mathrm{t})$ meets the requirements to be an IMF, if yes, then the IMF $\phi(t)=\mathrm{P}_{\mathrm{mfl}}(\mathrm{t})$. If not repeat steps $1-4$ on $\mathrm{P}_{\mathrm{mfl}}$ until it becomes an IMF.

6. Calculate the first residue $r_{1}(t)$, $\mathrm{r}_{1}(\mathrm{t})=\mathrm{S}(\mathrm{t})-\phi(t)$

7. Test whether the maximum amplitude of the residue is below a threshold or the number of local maxima or minima less than four, if so terminate the EMD process, otherwise repeat steps $1-6$ on the residue $r_{1}(t)$.

Fig. 1 provides a simple illustration of the EMD process. The maxima and minima of the signal $\mathrm{S}(\mathrm{t})$ is first obtained using the spline interpolation, the means of these splines are then found and subtracted from the $\mathrm{S}(\mathrm{t})$ giving $\mathrm{P}_{\mathrm{mf}}$, shown in Fig. 1(b) which is not yet an IMF, because its local mean is not zero. The above steps need to be repeated to process $\mathrm{P}_{\mathrm{mf}}$ so that it satisfies the condition to be the first IMF. After 5 iterations, the first IMF is obtained as shown in Fig 1(c) where the conditions for being an IMF are met- (i) there is one zero between any two consecutive local extrema and (ii) the local mean is zero.

Once all the IMFs are obtained, each of the IMFs is then processed by the Hilbert Transform.

\section{The Hilbert Transform}

The Hilbert Transform (HT) [13], [14] of an IMF $x(t)$ of the continuous variable $\mathrm{t}$ is defined as:

$$
H[x(t)]=\frac{1}{\pi} P \int_{-\infty}^{\infty} \frac{x(\tau)}{t-\tau} d \tau
$$

where: $\mathrm{P}$ is the Cauchy Principal Value integral

It can be shown that, the Hilbert transform of a signal effectively produces an orthogonal signal that is phase shifted by 90 degrees from the original signal independent of the frequency of the signal [14].

Defining a signal $\mathrm{z}(\mathrm{t})$ as:

$$
z(t)=x(t)+H[x(t)]=x+j y=a(t) e^{j \theta(t)}
$$

The instantaneous frequency and amplitude of $z(t)$ can be calculated as follows [13], [14] :

Instantaneous Amplitude:

$$
a(t)=\sqrt{x^{2}+y^{2}}
$$

Instantaneous Phase:

$$
\theta(t)=\arctan \left(\frac{y}{x}\right)
$$



Fig. 1. The EMD process on a simple signal, (A) the signal to be processed with its maxima and minima, (B) the first proto-mode function, (C) the first IMF obtained.

Instantaneous Frequency

$$
\omega(t)=\frac{d \theta}{d t}
$$

In this way, the HT on a signal $\mathrm{x}(\mathrm{t})$ produces its instantaneous magnitude, frequency and phase.

For stationary signals, to avoid the end-effects from the spline interpolation, in our simulation, the first and the last cycle of the HT result are not used and the amplitude, frequency and phase of the signal are calculated as constants which are equal to the means of the instantaneous amplitude, frequency and phase over the remaining part of the signal.

\section{Applying HHT to a stationary Power Quality waveform with harmonics}

Table I shows the results from applying HHT to $\mathrm{S}(\mathrm{t})$ in (9):

$$
\mathrm{S}(\mathrm{t})=\sin \left(2 \pi 50 \mathrm{t}+30^{\circ}\right)+0.33 \sin \left(2 \pi 150 \mathrm{t}+30^{\circ}\right)+
$$$$
0.09 \sin \left(2 \pi 550 \mathrm{t}+30^{\circ}\right)
$$

Table I shows that the results are very accurate in determining the instantaneous magnitude, frequency and phase.

TABLE I

RESULT OF HHT DECOMPOSITION OF S(T)
\begin{tabular}{|c|c|c|}
\hline $\mathrm{A}$ & $\mathrm{f}$ & 0 \\
\hline 0.09 & 550 & 30 \\
\hline 0.33 & 150 & 31 \\
\hline 1.00 & 50 & 31 \\
\hline
\end{tabular}

E. Applying HHT to a stationary Power Quality waveform containing Flicker

The HHT is applied to a flicker disturbance described by the amplitude modulated signal given in (10):

$$
S(t)=\sin \left(2 \pi f_{1} t\right)\left(1+0.2 \sin \left(2 \pi f_{2} t\right)\right)
$$

where:

$\mathrm{f}_{1}=$ fundamental frequency set at $50 \mathrm{~Hz}$ and amplitude of $1 \mathrm{pu}$.

$\mathrm{f}_{2}=$ amplitude modulation frequency set at $48 \mathrm{~Hz}$ resulting in a flicker frequency of $2 \mathrm{~Hz}$ and amplitude of $0.2 \mathrm{pu}$.

Fig. 2 shows the signal $\mathrm{S}(\mathrm{t})$ and its IMFs, and Fig. 3(A) and (B) show the instantaneous amplitude and frequency of the resulting IMFs. Fig. 2 shows that the first IMF is the fundamental signal and the second IMF is the flicker waveform. Fig. 3 shows that HHT has correctly identified the fundamental and flicker signal instantaneous frequency and amplitude. 


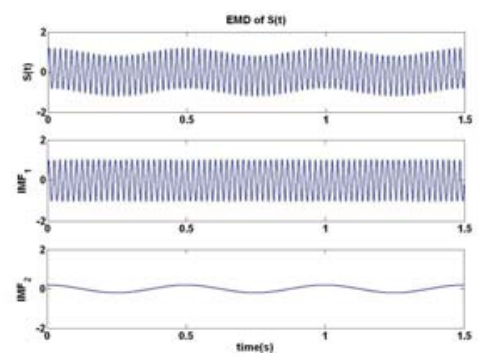

Fig. 2. The signal $\mathrm{S}(\mathrm{t})$ containing flicker and the resulting IMFs.

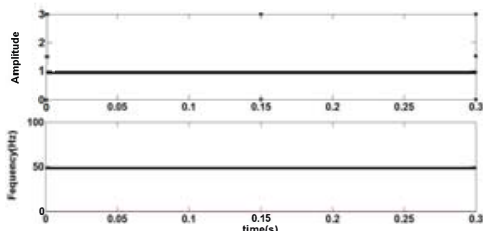

(A)

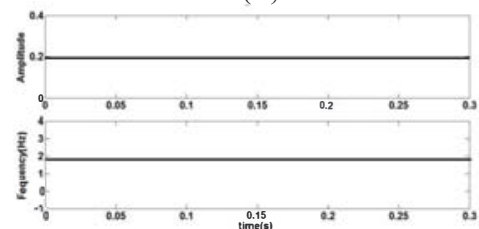

(B)

Fig. 3. (A) The instantaneous frequency and amplitude of the fundamental and (B) the flicker signal

\section{NON-STATIONARY SIGNAL}

\section{A. Applying HHT to a non-stationary Power Quality} waveform with harmonics

The HHT is applied to a signal containing harmonics given by:

$$
S(t)=\left\{\begin{array}{l}
\sin \left(2 \pi 50 t_{a}\right)+0.33 \sin \left(2 \pi 150 t_{a}\right), 0 \leq t_{a}<0.1 s \\
\sin \left(2 \pi 50 t_{b}\right)+0.2 \sin \left(2 \pi 250 t_{b}\right), 0.1 \leq t_{b}<0.2 s
\end{array}\right.
$$

The signal $\mathrm{S}(\mathrm{t})$ and the resulting IMFs obtained from the EMD process are given in Fig. 4. The associated instantaneous amplitudes and frequencies obtained from HT are given in Fig. 5.

It can be observed in Fig. 5, that although the HHT method can obtain automatically the instantaneous amplitude and frequency of both segments in the non-stationary signal (with segment 1 identified having freq $=50 \mathrm{~Hz}$ and $150 \mathrm{~Hz}$ with the instantaneous amplitude of $1 \mathrm{pu}$ and $0.33 \mathrm{pu}$ and segment 2 having freq $=50 \mathrm{~Hz}$ and $250 \mathrm{~Hz}$ with the instantaneous amplitude of $1 \mathrm{pu}$ and $0.2 \mathrm{pu}$ respectively), overshoot and ambiguity occur around the transition/discontinuity area.

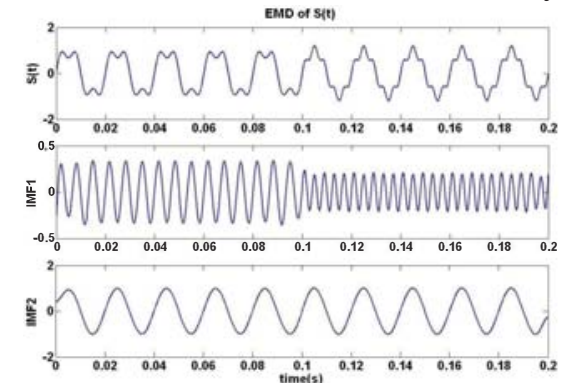

Fig. 4. The resulting IMFs of a harmonic signal $\mathrm{S}(\mathrm{t})$


Fig. 5. The resulting instantaneous amplitude and frequency of a harmonic signal.

B. Applying HHT to a non-stationary Power Quality signal containing harmonics and voltage sag

Fig. 6(A) shows a harmonic signal (with $50 \mathrm{~Hz}$ and $250 \mathrm{~Hz}$ components and amplitudes of $1 \mathrm{pu}$ and $0.2 \mathrm{pu}$ respectively), with a sag occurring at $0.1 \mathrm{sec}$ for 5 cycles at $50 \%$ of the original magnitude of each frequency. The signal $\mathrm{S}(\mathrm{t})$ was decomposed into its components and Fig. 6(B) and 6(C) show the IMFs of signal $\mathrm{S}(\mathrm{t})$. Fig. 7 shows the HT of the resulting IMFs. Again it can be observed that the HHT has correctly identified the instantaneous amplitudes and frequencies each segment but overshoot and ambiguity occur around the instants of sudden changes in the waveform.

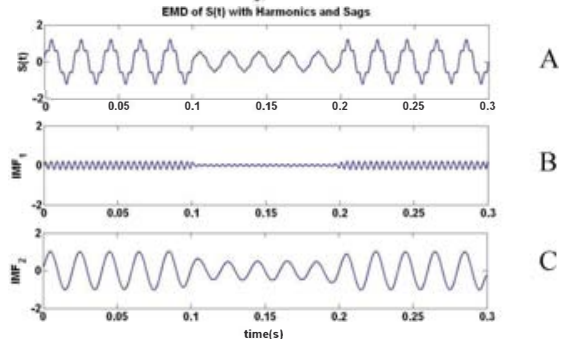

Fig. 6. The EMD process on a signal with harmonics and sag. (A) The signal $\mathrm{S}(\mathrm{t})$, (B) The first IMF of $\mathrm{S}(\mathrm{t})$ which contains the $250 \mathrm{~Hz}$ component of the signal, (C) The second IMF of S(t) containing the $50 \mathrm{~Hz}$ component
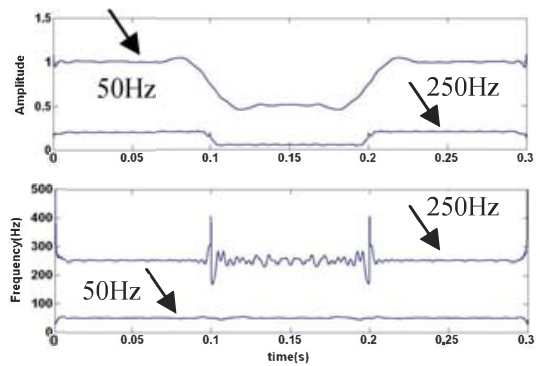

Fig. 7. (A) Instantaneous Amplitudes, (B) Instantaneous frequencies from the HT of IMFs in Fig. 4.

\section{Windowing Method to overcome ambiguity at transitions}

To overcome the ambiguity at the instant of transition, a windowing technique was developed. To identify the boundaries, the HHT is performed over a portion of the signal $\mathrm{S}(\mathrm{t})$, say from $0.0-0.02,0.02-0.04 \mathrm{sec}$ and so on. If a sudden change in frequency or amplitude is detected in the first IMF then the point where the change occurred is marked as a border for a window. In this example $0.1 \mathrm{sec}$ would have been marked as such a border. Having the border information, the signal decomposition could then be performed by using the 
HHT again from $0.0-0.1 \mathrm{sec}$. Then the process starts again from 0.1-0.2 sec. The result of the windowing technique for signal $\mathrm{S}(\mathrm{t})$ in (11) is shown in Fig. 8. Since the boundary has been detected, again the first and the last cycle can be eliminated and the amplitude, frequency and phase of the HT can be calculated as constants and equal to the means of the instantaneous amplitude, frequency and phase respectively over the remaining part of each stationary signal.

Fig. 8 show the two distinct segments for the instantaneous amplitude and frequency plots for the signal $\mathrm{S}(\mathrm{t})$ given in (11). $\mathrm{IMF}_{1}$ produces a signal with amplitude $=0.33 \mathrm{pu}$ and frequency $=150 \mathrm{~Hz}$ from 0 to $0.1 \mathrm{sec}$ and then a second signal with amplitude $=0.2 \mathrm{pu}$ and frequency $=250 \mathrm{~Hz}$ from $0.1 \mathrm{sec}$ to $0.2 \mathrm{sec}$. $\mathrm{IMF}_{2}$ produces a constant signal with amplitude $=$ $1 \mathrm{pu}$ and frequency $=50 \mathrm{~Hz}$ from $0-0.2 \mathrm{sec}$.
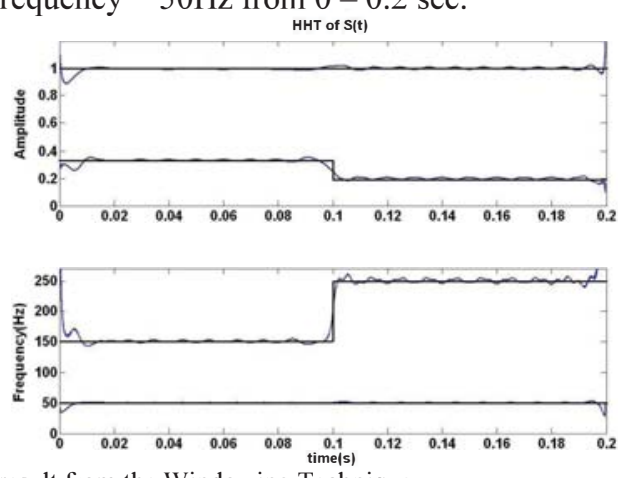

Fig. 8. The result from the Windowing Technique

To demonstrate further the usefulness of this technique, the HHT method with windowing technique is applied to a nonstationary signal which contains 3 segments of stationary signal as shown in table II. The non-stationary signal is sampled at a sampling period $\mathrm{t}_{\mathrm{s}}=2.10^{-4} \mathrm{sec}$ to obtain 1500 sample points with the boundary of the first and second segment occurring at $t_{1}=0.10 \mathrm{sec}$ and the boundary of the second and third segment occurring at $t_{2}=0.20 \mathrm{sec}$ as shown in Fig. 9(A).

By using the windowing technique, the boundaries are detected at $t_{1}=0.100 \mathrm{sec}$ and $t_{2}=0.200 \mathrm{sec}$. The plot of the detected amplitudes and frequencies of the non-stationary signal by using HHT are shown in Fig. 9(B) and 9(C). The value of detected amplitudes and frequencies are shown in Table III.

TABLE II

THE NON-STATIONARY SIGNAL CONTAINING 3 SEGMENTS

\begin{tabular}{|c|r|r|r|r|r|r|r|r|r|}
\hline \multicolumn{2}{|c|}{$\begin{array}{c}\text { Fundamental, } 3^{\text {rd }} \text { and } \\
7^{\text {th harmonic }}\end{array}$} & \multicolumn{2}{|c|}{$\begin{array}{c}\text { Fundamental, } 5^{\text {th }} \text { and } \\
11^{\text {th }} \text { harmonic }\end{array}$} & \multicolumn{3}{|c|}{$\begin{array}{c}\text { Fundamental, } 3^{\text {rd }} \text { and } \\
9^{\text {th }} \text { harmonic }\end{array}$} \\
\hline \multicolumn{2}{|c|}{ 0s $\leq \mathrm{t} \leq 0.0098 \mathrm{sec}$} & \multicolumn{2}{|c|}{$0.10 \mathrm{~s} \leq \mathrm{t} \leq 0.1098 \mathrm{~s}$} & \multicolumn{3}{|c|}{$0.20 \mathrm{~s} \leq \mathrm{t} \leq 0.30 \mathrm{~s}$} \\
\hline $\mathrm{A}$ & $\mathrm{f}$ & $\varphi$ & $\mathrm{A}$ & \multicolumn{1}{|c|}{$\mathrm{f}$} & $\varphi$ & $\mathrm{A}$ & $\mathrm{f}$ & $\varphi$ \\
\hline 282.84 & 50 & 0 & 282.84 & 50 & 0 & 282.84 & 50 & 0 \\
\hline 93.34 & 150 & 0 & 56.57 & 250 & 0 & 93.34 & 150 & 0 \\
\hline 40.41 & 350 & 0 & 25.74 & 550 & 0 & 31.112 & 450 & 0 \\
\hline
\end{tabular}

TABLE III

THE DETECTED AMPLITUdES AND FREQUENCIES USING THE HHT AND WINDOWING TECHNIQUE

\begin{tabular}{|c|c|c|c|c|c|c|c|c|}
\hline \multicolumn{2}{|c|}{$\begin{array}{c}\text { Fundamental, } 3^{\text {rd }} \text { and } \\
7^{\text {th }} \text { harmonic }\end{array}$} & \multicolumn{2}{c|}{$\begin{array}{c}\text { Fundamental, } \\
11^{\text {th }} \text { harmonic }\end{array}$} & \multicolumn{3}{|c|}{$\begin{array}{c}\text { Fundamental, } 3^{\text {rd }} \text { and } \\
9^{\text {th }} \text { harmonic }\end{array}$} \\
\hline A & f & $\varphi$ & A & f & $\varphi$ & A & f & $\varphi$ \\
\hline 282.5 & 50 & 0 & 283.43 & 50 & 1 & 282.00 & 50 & 1 \\
\hline 92.90 & 150 & 0 & 56.31 & 250 & 0 & 93.89 & 150 & 0 \\
\hline 40.20 & 350 & 1 & 26.31 & 550 & 0 & 31.53 & 450 & 0 \\
\hline
\end{tabular}



A

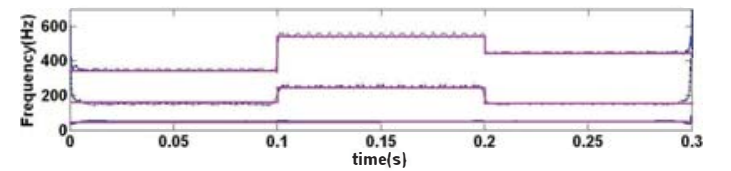

Fig 9 (A) The non-stationary Signal (B) The identified amplitude (c) The identified Frequency

While the windowing technique can solve the ambiguity issues associated with the instant of transitions occurring at the end of a cycle, the windowing technique of HHT may have difficulties when the instants of transitions occur in between the cycle.

\section{THE SAX ALGORITHM FOR NON-STATIONARY SIGNAL}

\section{A. Introduction}

To obtain the instants when there are sudden changes at any point in the waveform, a new symbolic aggregate approximation (SAX) analysis is used in this paper, in which the signal is converted into a series of symbols. A pattern detection algorithm is used to identify the instants when the pattern changes. Once the instants of sudden changes have been identified, the non-stationary signal could then be divided into a sequence of stationary signals. The HHT could then be applied to decompose each of the stationary signals.

\section{B. The Algorithm}

For a time series $\mathrm{C}$ of length $\mathrm{n}$ with the elements $\mathrm{c}_{1}, \mathrm{c}_{2}, \ldots . \mathrm{c}_{\mathrm{n}}$, the SAX representation [15] of $\mathrm{C}$ can be obtained by normalizing the $\mathrm{n}$-dimensional time series data and then converting it into a $\mathrm{w}$-dimensional time series $\mathrm{D}$ that has the elements $d_{1}, d_{2} \ldots d_{w}$ according to Eq.(12). Typically, $w<<$ n.

$$
d_{i}=\frac{w}{n} \sum_{j=\frac{n}{w}(i-1)+1}^{\frac{n}{w} i} c_{j}
$$

where $\quad w=$ window size

$$
n=\text { length of the signal }
$$

This simple representation is known as Piecewise Aggregate Approximation (PAA), which is the first step in obtaining the SAX representation. The next step is to transform the lower dimensional time series $\mathrm{D}$ to a number of equiprobable symbols assuming Gaussian distribution since normalized time series data usually show a highly Gaussian distribution characteristic [16].

To have the equiprobable symbols, equal sized areas under Gaussian curve need to be determined by defining breakpoints which will divide the curve to equiprobable regions.

To convert the PAA representation of a time series to symbols containing alphabets of "a" symbols, then $(\mathrm{a}-1)$ 
number of breakpoints have to be determined in order to divide the region under the Gaussian curve to "a" equally sized areas. The breakpoints are a sorted list of numbers $\mathrm{B}=$ $\beta_{1}, \ldots, \beta_{\mathrm{a}-1}$ such that the area under a Gaussian curve from $\beta_{\mathrm{i}}$ to $\beta_{i+1}=1 /$ a. Table IV shows a statistical table containing breakpoints that divides a Gaussian distribution in an arbitrary number [15].

TABLE IV

A LOOKUP TABLE THAT CONTAINS THE BREAKPOINTS THAT DIVIDES A GAUSSIAN DISTRIBUTION IN AN ARBITRARY NUMBER (FROM 3 TO 5) OF EQUIPROBABLE REGIONS [16]

\begin{tabular}{|c|c|c|c|}
\hline \multirow[b]{2}{*}{$\beta_{1}$} & 3 & 4 & 5 \\
\hline & -0.43 & -0.67 & -0.84 \\
\hline$\beta_{2}$ & 0.43 & 0 & -25 \\
\hline$\beta_{3}$ & & 0.67 & 0.25 \\
\hline$\beta_{4}$ & & & 0.84 \\
\hline
\end{tabular}

Fig 10 shows an example of a time series which need to be discretized to a PAA approximation using window size $\mathrm{w}=$ 10. The discrete representation then are symbolized using an alphabet of three symbols $(a=3)$. For this, two or $(a-1)$ breakpoints can be determined by looking at Table IV, which are $\beta_{1}=-0.43$ and $\beta_{2}=0.43$. $\left(\beta_{0}\right.$ and $\beta_{\mathrm{a}}$ are defined as $-\infty$ and $\infty$, respectively).

The concatenation of symbols from the PAA representation is called the SAX word, the total number of symbols used in SAX word is called word size, and the total number of discrete symbols possible is called alphabet size.

\section{THE NON-STATIONARY SIGNAL DECOMPOSITION USING SAX-BASED DECOMPOSITION}

To test the ability of SAX - based HHT algorithm to decompose a non-stationary harmonic signal, the same nonstationary signal as shown in Fig. 9 will be used. The details of each segment in the non-stationary signal are shown in Table II. The instants of the transitions are chosen as: $t_{1}=$ $0.1016 \mathrm{sec}$ and $t_{2}=0.2014 \mathrm{sec}$. The non-stationary harmonic signal, whose frequency, amplitude and phase change over time, is first converted to SAX representation to determine the boundaries of each segment. The boundaries locations need to be evaluated to divide the non-stationary signals to segments containing stationary signals only. Once obtained, each of the segments of stationary signals can then be decomposed using the decomposition method. The resulting SAX representation for the non-stationary signal is shown in Fig. 11.

In this paper, a window size of $1 \quad(\mathrm{w}=1)$ is used, that means the 1500-points signal will be converted to a PAA approximation of 1500 windows, each containing 1 data point The whole time series will then be represented by a SAX word containing 1500 characters. To improve the accuracy, 94 different alphabets are used and hence the alphabet size is 94 .

As the stationary signals in each time segment are periodic, the time series word for each period is repeated after each cycle of the SAX word representation. The word representing a cycle of signal can then be determined accordingly. For example, in Fig. 11, each cycle is a word with 100 characters.



Fig. 10. The process to discretize the time series or signal (thin black line) to obtain a PAA approximation (heavy gray line) and then to convert the PAA coefficients into symbols (bold letters) by using the predetermined breakpoints. In the example above, with $\mathrm{n}=80, \mathrm{w}=10$ and $\mathrm{a}=3$, the signal is mapped to an word-size of 8 SAX representation "cbaabcbb", adapted from [15]

Having converted the non-stationary signal into SAX representation, the patterns or motifs of repeating symbols could then be detected from which the time when the pattern changes denote the boundary time for each stationary signal.



Fig. 11. The SAX Representation of the Signal

To facilitate the comparison process of the symbols, each of the SAX alphabets is given a numeric value, for example $\mathrm{a}=1, \mathrm{~b}=2$ and so on.

Then a SAX boundary detector algorithm is carried out to find the boundary time for each segment using a cycle by cycle comparison of the SAX numeric value within the word.

The criteria using the Euclidean distance of the two consecutive cycles is used to determine the boundary point. If the Euclidean distance of the two consecutive cycles is greater than zero at location $\mathrm{n}$, then the boundary point is $\mathrm{n}$.

For example, consider the SAX words of the two time series $S_{1}(n)$ and $S_{2}(n)$ from two consecutive cycles of the above signal given in Table $\mathrm{V}$. The locations of the SAX symbol in the first and second time series are $n_{1}$ and $n_{2}$ and the symbols in each time series are given by $l_{1}$ and $l_{2}$ respectively. The numerical values of each alphabet and the Euclidean distances are also given.

The criterion to determine the boundaries is by using the Euclidean distances of two points on two consecutive cycles. If the Euclidean distance of the points is greater than zero, then the boundary are located at the point on the later cycle.

Using the above criterion, the boundaries are detected at $n_{1}$ $=509$ and $\mathrm{n}_{2}=1008$ as indicated in Table $\mathrm{V}$. These points in SAX representation coincide with: $t_{1}=0.1016 \mathrm{sec}$ and $t_{2}=$ 
$0.2014 \mathrm{sec}$ and are the actual boundaries specified. The period of each cycle is $0.02 \mathrm{sec}$ in the original signal.

Once the instants of transitions are found, the signal is applied to HHT as three separate stationary segments and the result is given in Table VI. Table VI shows that the HHT has correctly identified the amplitude, frequency and phase of each segment.

\section{CONCLUSION}

The paper has described the Hilbert Huang technique for use in decomposing power quality waveforms. The results from the simulation show that the HHT method can determine accurately the instantaneous amplitude, frequency and phase of both stationary and non-stationary power quality waveforms. However, ambiguity at the instants of transitions cannot be avoided. While windowing technique can alleviate the issues of ambiguity at the transition points, boundary detection using SAX algorithm has been found to be effective in determining accurately the transitions points in a nonstationary signal allowing the non-stationary signal to be divided into segments containing only stationary signals.

TABLE V

THE SAX WORD FOR TWO CONSECUTIVE CYCLES

\begin{tabular}{|c|c|c|c|c|c|c|c|c|c|c|c|c|c|}
\hline \multicolumn{3}{|c|}{$S_{2}\left(n_{3}\right)$} & \multicolumn{3}{|c|}{$S_{2}\left(n_{2}\right)$} & \multirow{3}{*}{$\begin{array}{l}\text { Euclidean } \\
\text { Dist }\end{array}$} & \multicolumn{3}{|c|}{$S_{3}\left(n_{2}\right)$} & \multicolumn{3}{|c|}{$S_{2}\left(n_{3}\right)$} & \multirow{3}{*}{$\begin{array}{l}\text { Euclidean } \\
\text { Dist }\end{array}$} \\
\hline & symbol & & & $5 y \mathrm{mbol}$ & & & & 5ymbol & & & symbol & & \\
\hline$n_{q}$ & $\mathrm{~b}_{2}$ & val e & $\mathrm{n}_{3}$ & $\mathrm{I}_{2}$ & val e & & $n_{2}$ & $b_{3}$ & value & $n_{z}$ & $\mathrm{Is}_{\mathrm{s}}$ & val e & \\
\hline 507 & 77 & $\because$ & 407 & 77 & $\because$ & 0 & 1005 & 61 & 'Y' & 905 & 61 & 'Y' & 0 \\
\hline 508 & 80 & ' 6 ' & 408 & 80 & 'द' & 0 & 1006 & 59 & 'W' & 906 & 59 & 'W' & 0 \\
\hline 509 & 73 & '\&' & 409 & 82 & '> & -9 & 1007 & 58 & 'V' & 907 & 58 & 'V' & 0 \\
\hline 510 & 75 & $\because$ & 410 & 83 & $?$ & .8 & 1008 & 75 & $\because$ & 908 & 62 & $\mathrm{z}^{\prime}$ & 6 \\
\hline 511 & 76 & $\because$ & 411 & 84 & 'I' & -8 & 1009 & 73 & 4 & 909 & 69 & '\&' & 6 \\
\hline 512 & 77 & 'द' & 412 & 85 & 11 & -8 & 1010 & 71 & $\pi$ & 910 & 75 & $\because$ & 5 \\
\hline 513 & 77 & 'द' & 413 & 85 & "1' & .8 & 1011 & 69 & '\&' & 911 & 79 & $\because$ & 6 \\
\hline- & - & - & - & - & - & - & 1012 & 69 & '\&' & 912 & 80 & $\bar{k}^{\prime}$ & 8 \\
\hline
\end{tabular}

TABLE VI

RESULT OF HHT DECOMPOSITION OF THE SIGNAL

\begin{tabular}{|c|c|c|c|c|c|c|c|c|}
\hline \multicolumn{3}{|c|}{$\begin{array}{c}\text { Fundamental }, 3^{\text {rd }} \\
\text { and } 7^{\text {th }} \text { harmonic }\end{array}$} & \multicolumn{3}{c|}{$\begin{array}{c}\text { Fundamental, } 5^{\text {th }} \text { and } \\
11^{\text {th }} \text { harmonic }\end{array}$} & \multicolumn{3}{c|}{$\begin{array}{c}\text { Fundamental, } 3^{\text {rd }} \text { and } 9^{\text {th }} \\
\text { harmonic }\end{array}$} \\
\hline$A$ & $\mathrm{f}$ & $\varphi$ & $\mathrm{A}$ & $\mathrm{f}$ & $\varphi$ & $\mathrm{A}$ & $\mathrm{f}$ & $\varphi$ \\
\hline 282.39 & 50 & 0 & 282.98 & 50 & 1 & 282.03 & 50 & 1 \\
\hline 93.76 & 150 & 0 & 55.75 & 250 & 0 & 93.65 & 150 & 1 \\
\hline 40.44 & 350 & 1 & 26.34 & 550 & 0 & 31.52 & 450 & 1 \\
\hline
\end{tabular}

\section{REFERENCES}

[1] D. D. Sabin and A. Sundarm, "Quality enhances reliability," IEEE Spectrum, vol. 33, pp. 34-41, 1996.

[2] A. Domijan, G. T. Heydt, A. P. S. Meliopoulos, S. S. Venkata, and S. West, "Directions of research on power quality," IEEE Transactions on Power Delivery, vol. 8, pp. 429-436, January 1993.

[3] J. Douglas, "Solving power quality problems," EPRI Journal, vol. 18 pp. 6-15, December 1993.

[4] R. Flores, "Signal processing tools for power quality event classification," Lic.Eng. thesis, School Elect. Eng, Chalmers Univ. Technol, Göteborg, Sweden, 2003.

[5] S. J. Huang, C. T. Hsieh, and C. L. Huang, "Application of mortlet wavelets to supervise power system disturbances," IEEE Transactions on Power Delivery, col. 14, vol. 1, pp. 235-243, January 1999.

[6] N. E. Huang, Z. Shen, S. R. Long, M. C. Wu, H. H. Shih, Q. Zheng, N. C. Yen, C. C. Tung, and H. H. Liu, "The empirical mode decomposition and the hilbert spectrum for nonlinear and nonstationary time series analysis," Proceedings of the Royal Society A:
Mathematical, Physical and Engineering Sciences, vol. 454, pp. 903995, March 1998.

[7] F. J. Harris, "On the use of windows for harmonic analysis with the discrete fourier transform," Proceedings of the IEEE, vol. 66, pp. 5183, 1978.

[8] O. Rioul and M. Vetterli, "Wavelets and signal processing," IEEE Signal Process. Mag.8, pp. 14-38, 1991

[9] W. G. Morsi and M. E. El-Hawary, "Suitable Mother Wavelet for Harmonics and Interharmonics Measurements Using Wavelet Packet Transform," Electrical and Computer Engineering, 2007. CCECE 2007.Canadian Conference on, pp. 748 - 752, April 2007.

[10] J. Barros and R. I. Diego, "Application of the wavelet packet transform to the estimation of harmonic groups in current and voltage waveforms," IEEE Trans. Power Delivery, vol. 21, pp. 533-535, January 2006

[11] C. F. Drummond and D. Sutanto, "Classification of Power Quality Disturbances using the Hilbert Huang Transform," Harmonics and Quality of Power (ICHQP), 2010 14th International Conference on pp. 1-7, 2010.

[12] G. Rilling, P. Flandrin, and P. Gonçalves, "On Empirical Mode Decomposition and its algorithms," IEEE-EURASIP Workshop on Nonlinear Signal and Image Processing, NSIP-03, Grado (I), June 2003.

[13] R. Deering and J. Kaiser, "The use of a masking signal to improve empirical mode decomposition," ICASSP, vol. 4, pp. 485-488, 2005.

[14] S. L. Hahn, Ed., Hilbert Transforms in Signal Processing. London: Artech House, Boston, 1996.

[15] E. Keogh, J. Lin, and A. Fu, "HOT SAX: Efficiently Finding the Most Unusual Time Series Subsequence," Proceedings of the Fifth IEEE International Conference on Data Mining (ICDM'05), pp. 226233,2005

[16] J. Lin, E. Keogh, S. Lonardi, and B. Chiu, "A Symbolic Representation of Time Series, with Implications for Streaming Algorithms," 8th ACM SIGMOD Workshop on Research Issues in Data Mining and Knowledge Discovery Proceeding of, 2003.

\section{BIOGRAPHIES}

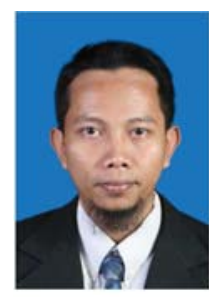

A Mohammad Jasa Afroni received his B.Eng degree from the University of Brawijaya, Indonesia in 1993 and M.Sc degree in electrical engineering from the Sepuluh Nopember Institute of Technology, Indonesia in 2000. He is currently pursuing the Ph.D. degree in harmonics and power-quality at the University of Wollongong, Wollongong, Australia. $\mathrm{He}$ is also currently an academic staff at the Islamic University of Malang, Indonesia since 1994.



Danny Sutanto (SM'08) received his B.Eng. (Hons.) and $\mathrm{Ph} . \mathrm{D}$. degrees from the University of Western Australia, Perth, Australia. Currently, he is the Professor of Power Engineering at the University of Wollongong, Wollongong, Australia. His research interests include power system planning, analysis and harmonics, flexible ac transmission systems (FACTS), and battery energy storage systems. He was the IEEE PES Region 10 Regional Representative in 2002-2004 and he is currently the IEEE IAS Region 10 Area Director.

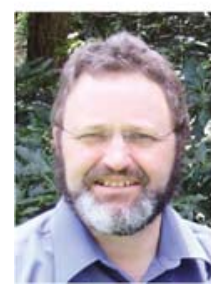

David Stirling obtained his BEng degree from the Tasmanian College of Advanced Education (1976). He further obtained his MSc degree (Digital Techniques) in Digital Techniques from Heriot-Watt University, Scotland UK (1980), and his PhD from the University of Sydney (1995). He has worked for over 18 years in wide range of industries, most recently as a Principal Research Scientist with BHP Steel. He has recently taken up a position as Senior Lecturer at the University of Wollongong. His research interests are in Machine Learning and data mining. 